\title{
PENINGKATAN EFISIENSI ENERGI SISTEM PENERANGAN PADA RUANG PERKULIAHAN DENGAN LAMPU LED BERDASARKAN ANALISIS ARUS CAHAYA
}

\author{
Muhammad Arkhan Pradanugraha ${ }^{1}$, Amien Rahardjo ${ }^{2, a}$, \\ Dwi Riana Aryani ${ }^{3, b}$, Faiz Husnayain ${ }^{4, c, *}$ \\ ${ }^{1,2,3,4}$ Departemen Teknik Elektro, Fakultas Teknik, Universitas Indonesia, Indonesia \\ ${ }^{\mathrm{a}, \mathrm{b}, \mathrm{c}}$ Electric Power and Energy Studies (EPES), Universitas Indonesia, Indonesia \\ *Email:faiz.h@ui.ac.id
}

\begin{abstract}
Abstrak
Penelitian peningkatan efisiensi energi selalu menjadi salah satu riset yang terus berkembang, termasuk pada sistem penerangan. Tidak sedikit sistem penerangan pada ruang perkuliahan saat ini yang nilainya masih dibawah standar. Sistem penerangan merupakan salah satu faktor pendukung penting kegiatan perkuliahan. Penelitian ini bertujuan untuk mensimulasikan peningkatan efisiensi energi serta tingkat penerangan melalui analisis arus pencahayaan pada ruang perkuliahan Gedung K FTUI dengan dua tahapan. Pertama, melakukan pengukuran iluminasi semua ruang kuliah. Selanjutnya, mengevaluasi tingkat pencahayaan dengan analisis arus cahaya pada software dialux. Skenario yang digunakan yaitu penggantian jenis lampu yang dipakai dengan LED dan perubahan jumlah titik lampu yang terpasang. Hasil simulasi menunjukkan penggunaan lampu LED dengan arus cahaya sebesar 2500 lumen efektif meningkatkan tingkat pencahayaan ruang. Selain itu terjadi peningkatan efisiensi energi sebesar $40 \%$ dengan adanya penggantian lampu dari sebelumnya $2.240 \mathrm{kWh}$ menjadi $1.339,2 \mathrm{kWh}$.
\end{abstract}

Kata kunci: arus cahaya, tingkat pencahayaan, konsumsi energi, LED, ruang perkuliahan

\begin{abstract}
Research on energy efficiency improvement has always been one of the emerging topic, including in lighting systems. Currently, there are many lighting system's quality in lecture halls that are still below standard. The lighting system is one of the important supporting factors supporting lecture activities. This study aims to simulate an increase in energy efficiency and lighting levels through the analysis of current lighting in the lecture room of the Gedung-K FTUI with two stages. First, measure the illumination of all lecture halls. Next, evaluate the lighting level with light flow analysis in dialux software. The scenario used is the replacement of the existing lamp's type used to LED lamp and the modification of light points installed. The simulation results show that the use of LED lamps with a light current of 2500 lumens is effective in increasing the level of room lighting. In addition, there was an increase in energy efficiency by $40 \%$ with the replacement of lamps from the previous of energy usage of $2,240 \mathrm{kWh}$ to $1,339.2 \mathrm{kWh}$.
\end{abstract}

Keywords: luminous flux, illumination, energy consumption, LED, lecture hall

\section{Pendahuluan}

Saat ini, tidak sedikit ruang perkuliahan di Indonesia yang memiliki kualitas pencahayaan masih dibawah standar dengan konsumsi energi yang tinggi. Tidak dapat dipungkiri, tingkat pencahayaan ruang belajar yang tepat merupakan salah satu faktor utama penunjang kegiatan pembelajaran. Hal ini dikarenakan tingkat pencahayaan ruang yang tepat dapat mempengaruhi psikologis dan emosional [1]. Selain itu, pada studi lain mengatakan dengan pencahayaan ruang tertinggi sebesar 750 lux dapat menyebabkan kelelahan pada mata [2]. Saat ini penggantian sumber penerangan konvensional umumnya menggunakan lampu berjenis light emitting diode (LED) baik untuk penerangan dalam ruangan maupun luar ruangan. Salah satu kelebihan lampu berjenis LED adalah penghematan energi pada gedung-gedung publik, salah satunya pada sektor pendidikan [3]. Pengaturan intensitas cahaya pada suatu ruangan juga harus disesuaikan dengan fungsi agar mata tidak cepat lelah atau kemungkinan terburuk dapat menimbulkan kerusakan permanen pada mata [4].

LED merupakan suatu bahan semikonduktor yang akan memancarkan cahaya monokromatik dengan prinsip kerja pemberian tegangan maju (forward bias) dimana adanya aliran elektron dari $\mathrm{p}$ type menuju $\mathrm{n}$ type dalam kondisi close loop melalui depletion layer yang tipis [5, 6]. LED 
memiliki degradasi pemakaiannya lebih lama apabila dibandingkan dengan sumber penerangan lain. Namun, dalam melakukan pengemasan harus adanya manajemen panas yang baik agar hasil cahaya yang dikeluarkan lampu tetap maksimal, sehingga faktor ini membuat beberapa industri membuat LED yang tahan lama dan andal [7, 8]. Penggunaan LED memiliki kelebihan yaitu ramah lingkungan, dapat menciptakan suasana yang beragam, dan hemat daya. Sehingga dapat dikatakan LED merupakan sumber penerangan yang ekonomis dan ramah lingkungan [9]. Dengan adanya perubahan jenis lampu maka jumlah konsumsi energi yang digunakan oleh lampu dapat berkurang [10]. Beberapa gedung publik seperti gedung olahraga atau pendidikan masih belum banyak aplikasi pencahayaan LED, padahal pencahayaan dapat meningkatkan kinerja dan kenyamanan sesuai dengan desain yang digunakan pada ruangan [11]. Apabila ada gedung olahraga yang sudah menggunakan lampu LED pun memiliki tingkat pencahayaan yang sangat tinggi yang berdampak pada tingkat silau dan ketidaknyamanan mata manusia [12].

Penelitian ini bertujuan untuk mensimulasikan peningkatan efisiensi energi serta tingkat penerangan melalui analisis arus pencahayaan pada ruang perkuliahan Gedung K FTUI dengan dua tahapan. Pertama, melakukan pengukuran iluminasi semua ruang kuliah. Selanjutnya, mengevaluasi tingkat pencahayaan dengan analisis arus cahaya pada software dialux. Skenario yang digunakan yaitu penggantian jenis lampu yang dipakai dengan LED dan perubahan jumlah titik lampu yang terpasang. Software dialux yang merupakan opensource digunakan dalam menata titik lampu, menghitung kuat pencahayaan hingga konsumsi daya yang dibutuhkan. Sehingga diakhir penelitian didapatkan peningkatan efisiensi konsumsi energi pada gedung K FTUI dengan skenario yang dilakukan.

Artikel ini dibagi menjadi empat bagian. Bagian pertama menjelaskan mengenai teknologi LED saat ini pada gedung perkuliahan. Bagian kedua menjelaskan diagram alir, program simulasi, skenario penggantian lampu pada ruang perkuliahan, dan klasifikasi tipe ruang yang diukur dan disimulasikan. Selanjutnya bagian ketiga menjelaskan hasil simulasi pencahayaan software dialux berupa peta persebaran cahaya, analisis arus cahaya dengan metode perhitungan lumen dan analisis konsumsi energi. Bagian keempat merupakan kesimpulan dari studi.

\section{Metode}

\subsection{Diagram Alir}

Penelitian ini bertujuan untuk meningkatkan efisiensi energi sistem penerangan pada ruang perkuliahan.
Langkah penelitian dapat dilihat seperti yang tertera pada gambar 1 mengenai diagram alir penelitian.

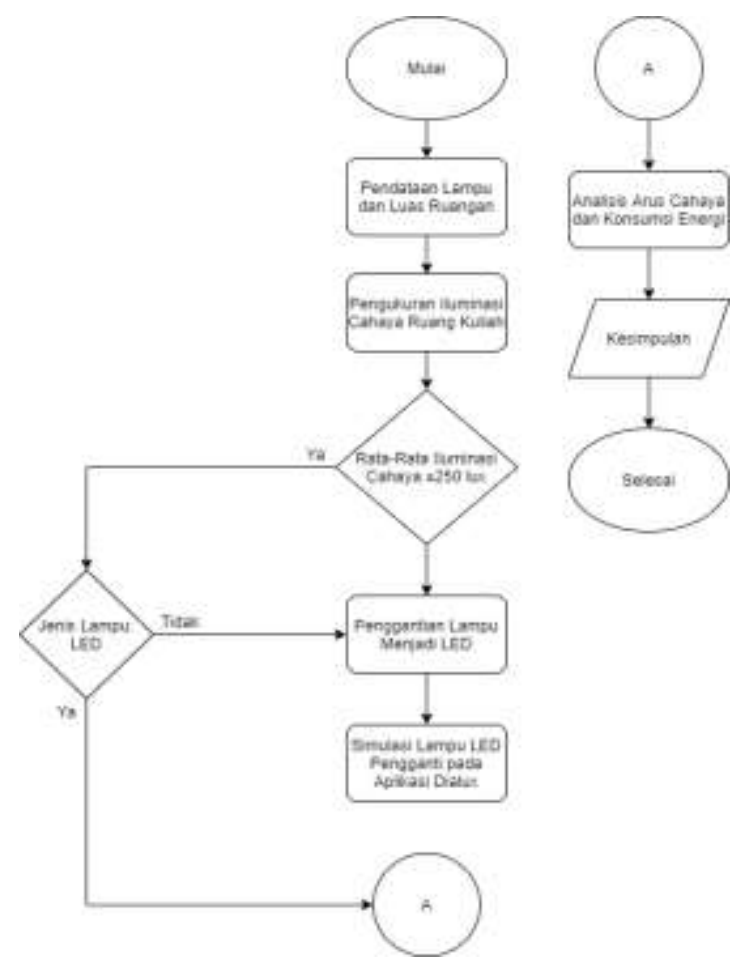

Gambar 1. Diagram Alir Penelitian

Langkah penggantian dengan cara mengukur rata-rata kuat penerangan dari lampu yang digunakan di ruang kuliah gedung K FTUI. Metode yang digunakan adalah pengukuran secara langsung menggunakan lux meter. Pengukuran dilakukan di atas bidang kerja meja kuliah. Pengukuran diambil pada beberapa titik pada ruangan untuk menentukan rata-rata tingkat pencahayaan dalam ruangan. Setelah didapat nilai rata-rata dari kuat pencahayaan suatu ruang, akan dibandingkan dengan standar pencahayaan yaitu sebesar 250 lux. Apabila ratarata kuat penerangan pada ruang tersebut adalah 250 lux dan masih menggunakan lampu selain LED, maka akan dilakukan penggantian menjadi lampu LED. Sedangkan ruang dengan rata-rata kuat penerangan di bawah 250 lux, akan dilakukan penggantian dengan lampu LED dan titik lampu pada ruangan tersebut. Setelah kuat penerangan semua ruang sudah sesuai dengan standar yang berlaku, maka dilakukan analisis arus cahaya dan analisis konsumsi energi untuk mengetahui dampak dari penggantian lampu yang dilakukan.

\subsection{Parameter Performa LED}

Rata-rata energi cahaya yang dipancarkan oleh sebuah sumber penerangan disebut juga dengan arus cahaya $(\Phi)$. Definisi dari arus cahaya adalah jumlah cahaya yang dipancarkan oleh sumber penerangan dalam satuan detik. Satuan dari arus cahaya adalah lumen [lm]. Terang atau 
redup suatu lampu dipengaruhi dari arus cahaya lampu tersebut. Semakin tinggi lumen dari lampu, maka akan semakin terang cahaya lampu yang dihasilkan. Hal tersebut dapat dinyatakan dalam persamaan, yaitu:

$$
\begin{aligned}
& \Phi=\frac{Q}{t} \\
& \Phi=\mathrm{W} \times \Phi_{\text {spesifik }}
\end{aligned}
$$

Dimana

$$
\begin{array}{ll}
\Phi & =\text { arus cahaya }[\mathrm{lm}] \\
\mathrm{Q} & =\text { energi cahaya }[\mathrm{lm} \cdot \mathrm{dt}] \\
\mathrm{t} & =\text { waktu }[\mathrm{dt}] \\
\Phi_{\text {spesifik }} & =\text { arus cahaya secara spesifik }[\mathrm{lm} / \mathrm{W}]
\end{array}
$$

Pada dasarnya, intensitas cahaya dengan besaran 1 candela akan setara dengan arus cahaya sebesar 1 lumen dalam satuan ukuran 1 steredian [13]. Berdasarkan aturan SNI 03-6575-2001, rata-rata pencahayaan minimum untuk ruang kelas dalam lembaga pendidikan adalah sebesar 250 lux. Sehingga dalam satu ruang kuliah dilakukan beberapa titik ukur dan akan diambil nilai ratarata untuk diketahui tingkat pencahayaan suatu ruangan. Pada studi ini juga dilakukan penentuan arus cahaya minimum pada lampu dalam ruang kuliah dengan metode perhitungan lumen, yaitu [14]:

$\Phi=\frac{E \times A}{\eta \times N}$

Dimana

$$
\begin{array}{ll}
\Phi & =\text { arus cahaya }[\mathrm{lm}] \\
\mathrm{E} & =\text { kuat pencahayaan }[\mathrm{lux}] \\
\mathrm{A} & =\text { luas ruangan }\left[\mathrm{m}^{2}\right] \\
\eta & =\text { koefisien pencahayaan } \\
\mathrm{N} & =\text { jumlah lampu yang digunakan }
\end{array}
$$

Komponen yang perlu diperhatikan dalam pencahayaan ruang kuliah adalah jenis pencahayaan lampu yang digunakan. Jenis pencahayaan ini akan menentukan koefisien pencahayaan yang digunakan dalam metode perhitungan lumen. Rendemen atau koefisien antara lain [14]:

a. Sistem penerangan langsung dengan koefisien $50 \%$.

b. Sistem penerangan setengah langsung dengan koefisien $40 \%$.

c. Sistem penerangan tidak langsung dengan koefisien $30 \%$.

Saat ini, manusia tidak terlalu mementingkan efekasi dari sebuah lampu, melainkan kenyamanan yang digunakan dari lampu tersebut karena dapat mempengaruhi psikologis manusia [15]. Energi listrik adalah sebagai elektron yang mengalir melalui sebuah bahan penghantar yang disebut konduktor. Satuan dasar dari energi listrik ini adalah joule $[\mathrm{J}]$ atau watthour [Wh]. Energi listrik merupakan laju penggunaan dari daya dalam beberapa waktu tertentu pada saat alat itu digunakan. Rumus dari energi listrik yaitu [16]:

$E=P \times t$

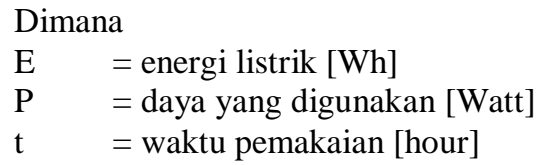

\subsection{Tipe Ruang Kuliah Gedung Fakultas Teknik Universitas Indonesia}

Jumlah ruang kuliah pada gedung K Fakultas Teknik Universitas Indonesia sebanyak 19 ruang. Pada studi ini dibagi menjadi empat tipe ruang berdasarkan luas ruang, yaitu:

a. Ruang kuliah tipe A dengan luas ruang sebesar 59,45 $\mathrm{m}^{2}$. Ruang kuliah tersebut antara lain K 101, K 104, K 105, K 108, K 201, K 203, dan K 208.

b. Ruang kuliah tipe B dengan luas ruang sebesar 55,1 $\mathrm{m}^{2}$. Ruang kuliah tersebut adalah K 205 .

c. Ruang kuliah tipe C dengan luas ruang sebesar 103,5 $\mathrm{m}^{2}$. Ruang kuliah tersebut antara lain K 209, K 210, dan K 211.

d. Ruang kuliah tipe D dengan luas ruang sebesar 121,7 $\mathrm{m}^{2}$. Ruang kuliah tersebut antara lain K 102, K 103, K 106, K 107, K 202, K 204, K 206, dan K 207.

\subsection{Skenario Penggantian}

Skenario penggantian lampu pada ruang kuliah ini adalah menggunakan simulasi pada Dialux. Penggantian lampu pada ruang ini berdasarkan perhitungan pada metode perhitungan lumen. Tujuan dilakukan skenario penggantian lampu ini adalah mengganti lampu TL fluoresen dengan TL LED agar dapat menghemat energi dan membuat tingkat pencahayaan pada ruang perkuliahan minimal 250 lux. Skenario ini dilakukan dengan membandingkan antara kondisi eksisting dengan kondisi setelah penggantian. Situasi ini dilakukan dengan mengganti jenis lampu kondisi eksisting dengan jenis lampu yang baru. Dalam ilmu ekonomi teknik, analisis penggantian dapat meningkatkan efisiensi dan persaingan perusahaan dalam bidang pencahayaan [17].

\subsubsection{Skenario 1}

Skenario satu merupakan penggantian jenis lampu tanpa perubahan titik lampu. Skenario ini akan dilakukan apabila memenuhi dua syarat, yaitu tingkat pencahayaan ruang perkuliahan tersebut telah memenuhi standar penerangan yang berlaku dan pada ruang tersebut masih menggunakan lampu TL fluoresen. Tujuan dari pengadaan skenario adalah melakukan penghematan daya yang digunakan oleh lampu. Penggantian ini dilakukan dengan mengganti lampu TL fluoresen yang dipakai saat ini dengan lampu TL LED. Hal ini dikarenakan pada teorinya, penggunaan dari lampu fluoresen menggunakan 
daya yang cukup besar dan memiliki gangguan harmonik yang cukup tinggi [18]. Penggantian ini tidak disertai dengan perubahan titik lampu yang telah terpasang. Pemilihan lampu pengganti disesuaikan dengan nilai arus cahaya lampu yang saat ini terpasang pada ruang perkuliahan. Lampu TL fluoresen yang saat ini dipakai adalah lampu X TL-D 36W/54-765 1SL/25 dengan arus lampu sebesar 2.500 lumen. Lampu TL LED pengganti yang akan digunakan pada simulasi adalah lampu X LED MASTER LEDtube 1200mm UO 15,5W 865 T8 dengan nilai arus cahaya sebesar 2.500 lumen. Pada skenario penggantian ini menggunakan simulasi pencahayaan alami. Simulasi pencahayaan alami ini dilakukan pada tiga waktu, yaitu pagi hari pukul 08.00, siang hari pada pukul 13.00, dan malam hari pada pukul 18.00. Pada pagi hari dan siang hari dilakukan simulasi dengan tidak menggunakan lampu yang ada di dalam ruangan. Sedangkan pada malam hari, lampu yang ada di dalam ruangan baru akan dinyalakan.

\subsubsection{Skenario 2}

Skenario dua merupakan penggantian jenis lampu dengan perubahan titik lampu. Hal ini dilakukan apabila kondisi ruang perkuliahan tersebut memiliki rata-rata tingkat pencahayaan ruang yang kurang dari standar pencahayaan. Standar pencahayaan pada penelitian ini adalah sebesar 250 lux. Hal yang dilakukan dalam skenario ini adalah melakukan penggantian lampu yang digunakan dan pengubahan titik lampu yang dipasang pada ruang kuliah tersebut. Titik lampu yang terpasang pada ruang diatur secara seimbang agar persebaran cahaya dapat merata. Penentuan jumlah lampu yang dipakai dalam skenario ini menggunakan metode perhitungan lumen. Metode perhitungan lumen dapat menentukan jumlah lampu yang digunakan dengan nilai arus cahaya tertentu. Selain itu, pada metode ini juga dapat menentukan nilai arus cahaya pada lampu sesuai dengan jumlah lampu yang terpasang pada ruangan tersebut. Lampu yang akan digunakan sebagai pengganti lampu sebelumnya adalah lampu TL LED X MASTER LEDtube 1200mm UO 15,5W 865 T8 dengan arus cahaya sebesar 2500 lumen. Hasil dari skenario ini adalah ruang perkuliahan yang memiliki pencahayaan sesuai dengan standar dan daya yang digunakan hemat. Pada skenario ini juga dilakukan simulasi dengan penggunaan pencahayaan alami yaitu menggunakan cahaya matahari. Pada studi ini, pencahayaan menggunakan cahaya matahari akan di simulasikan pada pagi hari pukul 08.00 waktu simulasi dan siang hari pada pukul 13.00 waktu simulasi pada alat bantu perangkat lunak Dialux. Penggunaan dari lampu pada ruang kuliah akan dilakukan pada malam hari.

\subsection{Simulator Dialux}

Aplikasi dialux dibuat oleh industri pengembang dari Jerman dengan nama DIAL GmbH Lüdenscheid. digunakan untuk merancang sistem penerangan ruangan, menghitung, dan memberikan gambaran secara visual dalam tiga dimensi terhadap penerangan yang dipasang pada ruangan. Pada aplikasi ini disediakan beberapa jenis luminer dan lampu yang dapat digunakan untuk mendesain ruang yang diinginkan. Hasil dari simulasi dari aplikasi adalah tingkat pencahayaan dari desain yang dibuat dalam titik tingkat pencahayaan pada suatu bidang kerja dalam satuan lux.

\section{Hasil dan Pembahasan 3.1. Peta Persebaran Cahaya}

Pada studi ini dilakukan pengukuran dan simulasi tingkat pencahayaan pada keempat tipe ruang kuliah pada gedung Fakultas Teknik Universitas Indonesia. Skenario pertama diperuntukkan bagi ruang perkuliahan yang sudah sesuai dengan standar pencahayaan yang berlaku. Sedangkan skenario kedua diperuntukkan untuk ruang perkuliahan yang masih kurang dari standar pencahayaan yang berlaku. Dari hasil pengukuran yang dilakukan pada studi ini, terdapat sembilan ruang kuliah yang memiliki pencahayaan kurang dari standar pencahayaan. Peta persebaran cahaya pada ruang K 101 akan menjadi salah satu contoh hasil skenario penggantian satu, sedangkan peta persebaran cahaya pada ruang K 205 merupakan salah satu contoh hasil simulasi dari skenario penggantian dua.

\subsubsection{Skenario Penggantian 1}

Pada skenario penggantian 1 dilakukan penggantian lampu tanpa mengubah titik lampu yang telah terpasang. Berdasarkan pengukuran pada studi ini, terdapat sebelas ruang kuliah yang telah memenuhi standar pencahayaan yang berlaku. Tipe ruang kuliah yang menggunakan skenario penggantian ini adalah ruang kuliah dengan tipe A, C, dan D. Pada studi ini, akan ditunjukkan salah satu hasil simulasi yang dilakukan pada ruang K 101 dimana ruang kuliah ini adalah ruang kuliah dengan tipe A. Lampu yang digunakan pada ruang kuliah ini adalah lampu TL fluoresen dengan merek X TL-D 36W/54-765 1SL/25. Sedangkan lampu pengganti yang akan digunakan adalah lampu TL LED dengan merek $\mathrm{X}$ MASTER LEDtube 1200mm UO 15,5W 865 T8. Kedua jenis lampu memiliki arus cahaya yang sama yaitu sebesar 2500 lumen. Hal yang membedakan dari kedua jenis lampu ini adalah konsumsi daya lampu. Konsumsi daya lampu eksisting sebesar 36W sedangkan untuk lampu pengganti sebesar 15,5 W. Hal ini sesuai dengan tujuan skenario penggantian ini yaitu melakukan penghematan energi. Simulasi dilakukan sebanyak tiga kali pada pagi hari, siang hari, dan malam hari berdasarkan waktu simulasi. Simulasi pagi hari dan siang hari adalah lampu ruang kuliah dimatikan, sehingga pencahayaan ruang hanya mengandalkan pencahayaan alami dari cahaya matahari. Sedangkan simulasi pada malam hari menggunakan pencahayaan penuh dari lampu yang 
terpasang pada ruang kuliah. Contoh simulasi akan dilakukan pada ruang kuliah tipe A (K 101).

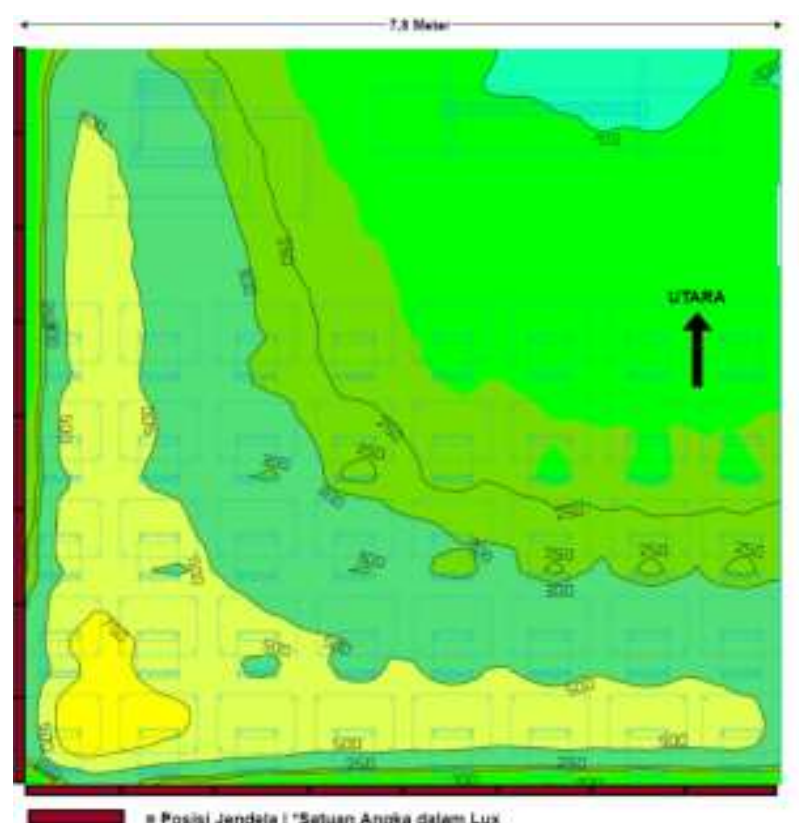

Gambar 2 Peta Persebaran Cahaya K 101 pada Pagi Hari (08.00)

Pada gambar 2 dapat dilihat terdapat beberapa area kontur dengan warna yang beragam berdasarkan tingkat pencahayaan dari bidang kerja. Area kontur berwarna kuning memiliki tingkat pencahayaan maksimal, karena posisi yang berdekatan dengan jendela ruang yaitu sisi kiri dan belakang ruang. Sedangkan area kontur yang berwarna hijau muda merupakan area yang mendapatkan tingkat pencahayaan terkecil karena lokasi yang cukup jauh dari posisi jendela. Hal yang membedakan dengan gambar 3 ialah waktu simulasi pada siang hari yang memiliki tingkat pencahayaan lebih tinggi dengan tingkat pencahayaan tertinggi pada area kontur berwarna jingga. Lalu untuk gambar 4 merupakan peta persebaran cahaya yang menggunakan lampu sebagai sumber pencahayaan ruang. Kontur-kontur ini terbentuk sebagai tingkat area distribusi cahaya pada ruang. Semakin dekat suatu bidang kerja dengan lampu yang terpasang maka akan semakin tinggi, dan sebaliknya apabila posisi bidang kerja jauh dari lampu maka akan rendah tingkat pencahayaannya. Rata-rata pencahayaan pada ruang ini mencapai diatas 250 lux dimana sudah sesuai dengan standar pencahayaan yang berlaku.

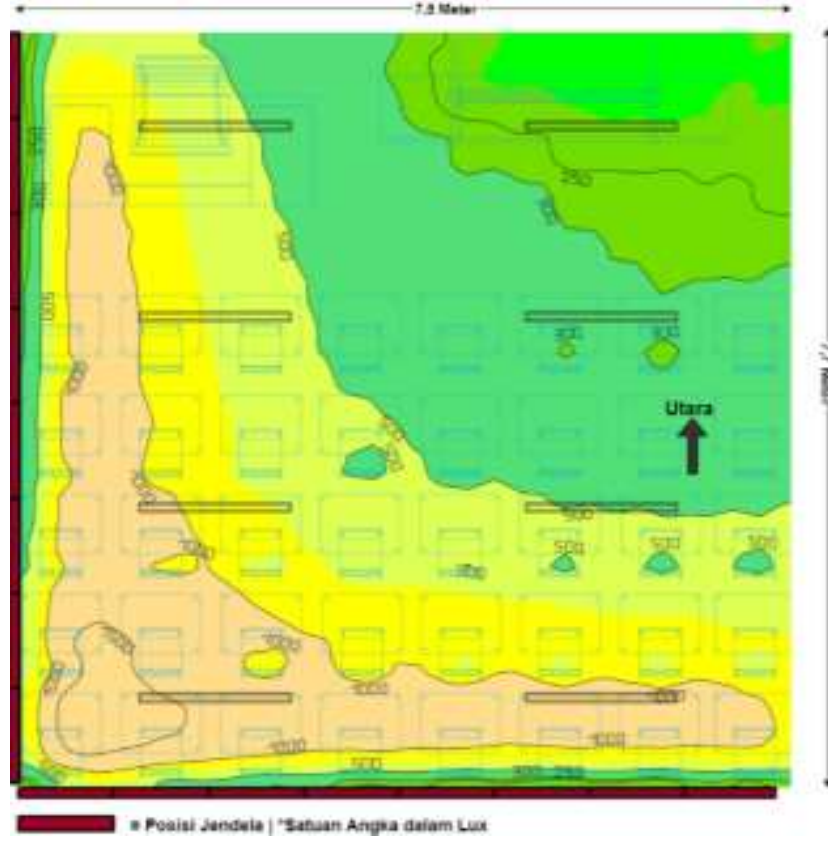

Gambar 3. Peta Persebaran Cahaya K 101 pada Siang Hari (13.00)

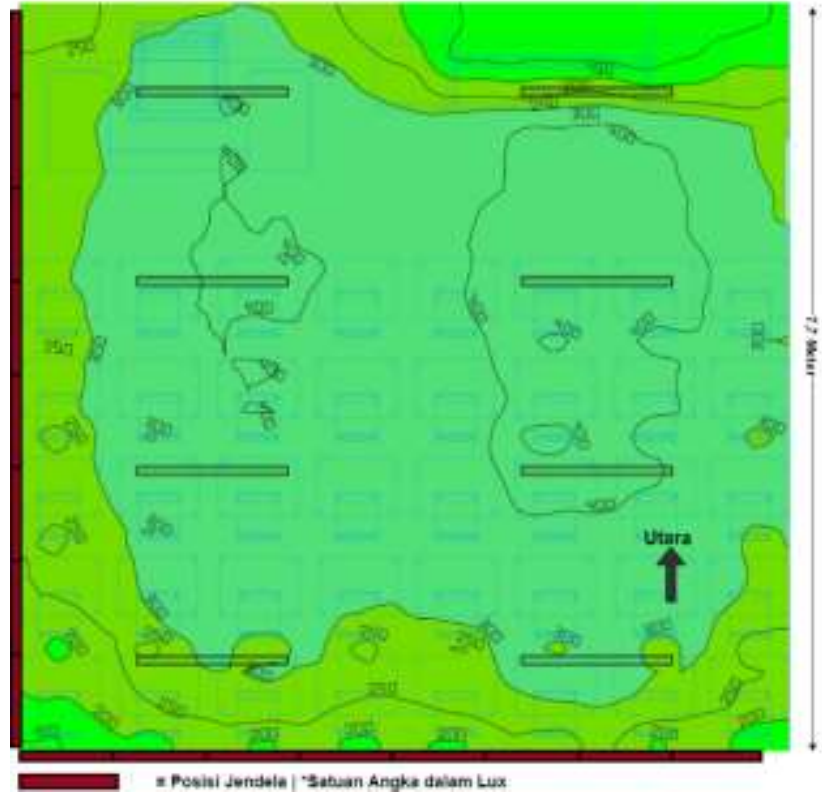

Gambar 4. Peta Persebaran Cahaya K 101 pada Malam Hari (18.00) 


\subsubsection{Skenario Penggantian 2}

Pada skenario penggantian kedua akan dilakukan penggantian lampu dan titik letak lampu pada ruang. Skenario ini dilakukan pada ruang perkuliahan yang memiliki tingkat pencahayaan di bawah standar pencahayaan yang berlaku. Dari hasil pengukuran pada gedung, terdapat sembilan ruang kuliah yang masih memiliki tingkat pencahayaan di bawah standar. Tipe ruang kuliah pada skenario ini adalah ruang kuliah tipe A, B, dan D. Lampu yang digunakan sebagai pengganti adalah lampu merek X MASTER LEDtube $1200 \mathrm{~mm}$ UO 15,5W $865 \mathrm{~T} 8$. Arus cahaya yang dihasilkan oleh lampu jenis ini adalah 2500 lumen. Jumlah dari titik letak lampu disesuaikan pada metode perhitungan lumen. Simulasi pencahayaan pada ruang dilakukan pada pagi hari, siang hari, dan malam hari. Pada pagi hari dan siang hari, lampu pada ruang kuliah dimatikan untuk memaksimalkan pencahayaan matahari. Sedangkan pada malam hari, pencahayaan penuh berasal dari cahaya lampu pada ruang. Satuan yang digunakan dalam simulasi ini adalah lux sebagai hasil simulasi tingkat pencahayaan pada ruang kuliah tersebut. Contoh simulasi yang digunakan pada skenario 2 adalah ruang kuliah tipe B yaitu ruang K 205 .

Berdasarkan gambar 5 dan 6, terdapat lima area kontur distribusi cahaya yang dibedakan dalam warna. Dimana area kontur berwarna kuning dan jingga memiliki tingkat pencahayaan tertinggi. Hal ini dikarenakan area kontur ini memiliki posisi dekat dengan jendela sehingga mendapatkan pencahayaan dari matahari lebih banyak. Semakin jauh bidang kerja dari posisi jendela maka akan semakin kecil tingkat pencahayaan bidang kerja tersebut seperti area kontur dengan warna hijau muda. Sedangkan untuk perubahan jumlah titik lampu dari kondisi eksisting dan setelah penggantian tidak berpengaruh pada pagi hari dan siang hari.
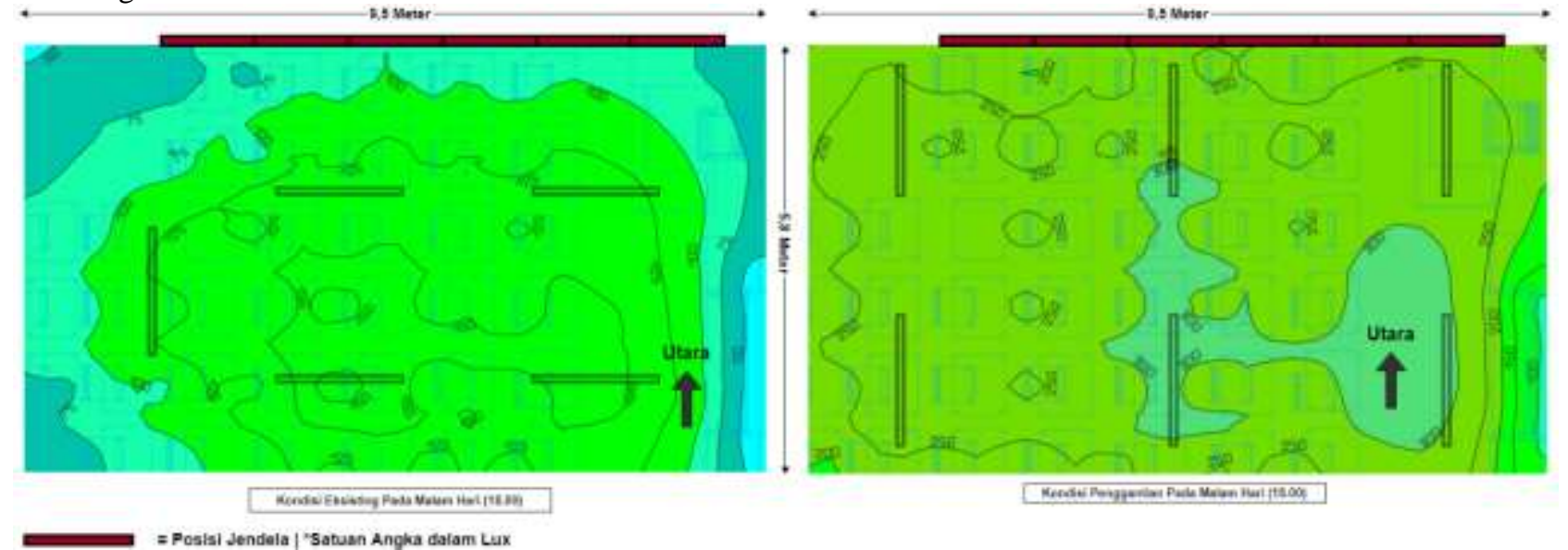

Gambar 7. Perbandingan Peta Persebaran Cahaya K 205 Pada Malam Hari (18.00) (Eksisting vs Penggantian) 
Pada gambar 7 terlihat bentuk kontur distribusi cahaya yang dihasilkan oleh lampu pada saat kondisi eksisting dan penggantian. Hal ini dikarenakan pada skenario penggantian 2 dilakukan penggantian jenis lampu kondisi eksisting dengan lampu dengan arus cahaya yang lebih besar dan titik lampu yang digunakan. Kontur distribusi cahaya setelah penggantian memiliki pencahayaan yang lebih merata dan sebagian besar titik pencahayaan sudah diatas standar pencahayaan, 250 lux. Walaupun, dalam ruang tersebut masih terdapat titik pencahayaan yang di bawah standar pencahayaan yaitu di sudut ruang kuliah dan memiliki posisi yang jauh dari lampu dengan area kontur berwarna hijau muda sampai biru. Apabila dibandingkan dengan pencahayaan dalam ruang yang menggunakan lampu fluoresen, penggunaan lampu LED dapat meningkatkan intensitas pencahayaan dan mengurangi konsumsi daya yang digunakan lampu [9].

\subsection{Analisis Hasil Arus Cahaya}

Tabel 1. Data Arus Cahaya Lampu Kondisi Eksisting dan Penggantian

\begin{tabular}{lccccc}
\hline Ruang & $\begin{array}{c}\text { Nilai } \\
\text { Minimum } \\
\text { Arus } \\
\text { Cahaya } \\
\text { [Im] }\end{array}$ & $\begin{array}{c}\text { Kuat } \\
\text { Pencahayaan } \\
\text { Lampu } \\
\text { Eksist [lux] }\end{array}$ & Ket & $\begin{array}{c}\text { Kuat } \\
\text { Pencahayaan } \\
\text { Lampu } \\
\text { Pengganti } \\
\text { [lux] }\end{array}$ & Ket \\
\hline K 101 & 1857,81 & 336,41 & Ok & 336.41 & Ok \\
K 102 & 1901,25 & 328,67 & Ok & 328,73 & Ok \\
K 103 & 1901,25 & 328,67 & Ok & 328,73 & Ok \\
K 104 & 1857,81 & 336,41 & Ok & 336,41 & Ok \\
K 105 & 1857,81 & 336,41 & Ok & 336,41 & Ok \\
K 106 & 1901,25 & 328,67 & Ok & 328,67 & Ok \\
K 107 & 2172,85 & 118,32 & Tidak Ok & 287,73 & Ok \\
K 108 & 1857,81 & 336,41 & Ok & 336,41 & Ok \\
K 201 & 1855 & 121,11 & Tidak Ok & 336,92 & Ok \\
K 202 & 2172,85 & 118,32 & Tidak Ok & 287,64 & Ok \\
K 203 & 1855 & 121,11 & Tidak Ok & 336,92 & Ok \\
K 204 & 2172,85 & 138,06 & Tidak Ok & 287,64 & Ok \\
K 205 & 2295,83 & 108,89 & Tidak Ok & 272,23 & Ok \\
K 206 & 2172,85 & 157,76 & Tidak Ok & 287,64 & Ok \\
K 207 & 2172,85 & 118,32 & Tidak Ok & 287,64 & Ok \\
K 208 & 1855 & 121,11 & Tidak Ok & 336,92 & Ok \\
K 209 & 2156,25 & 289,85 & Ok & 289,85 & Ok \\
K 210 & 2145 & 291,42 & Ok & 291,42 & Ok \\
K 211 & 2156,25 & 289,85 & Ok & 289,85 & Ok \\
\hline
\end{tabular}

Arus cahaya dapat diartikan sebagai jumlah cahaya yang dipancarkan oleh sumber penerangan dalam satuan detik. Satuan dari arus cahaya adalah lumen [lm]. Arus cahaya dari lampu tersebut akan mempengaruhi tingkat penerangan dari suatu ruangan. Mengacu pada persamaan (3), metode perhitungan lumen digunakan untuk mengetahui rekomendasi lumen lampu yang digunakan agar dapat memenuhi standar penerangan yang telah ditentukan, yaitu 250 lux. Seperti pada Ruang K 101 memiliki nilai minimum penggunaan sebuah lampu sebesar 1857,8 lumen dengan delapan titik lampu pada kondisi eksisting. Sedangkan lampu eksisting adalah jenis fluoresen dan digantikan oleh lampu jenis LED yang memiliki arus cahaya yang sama dengan tujuan untuk mengurangi daya yang digunakan. Sedangkan pada ruang
K 205 memiliki nilai minimum penggunaan lampu sebesar 2295,83 lumen dengan posisi enam titik lampu. Sedangkan kondisi lampu eksisting menggunakan lampu jenis LED dengan arus cahaya sebesar 1200 lumen dalam posisi lima titik lampu. Untuk mencapai kuat penerangan ruang yang sesuai dengan standar, maka diperlukan perubahan titik lampu sebanyak enam titik dan lampu dengan arus cahaya sebesar 2500 lumen. Penghitungan arus cahaya minimum pada sebuah lampu di ruang perkuliahan lainnya, dapat dilihat pada tabel 1 .

Pada tabel 1 dipaparkan mengenai kesesuaian antara hasil metode perhitungan lumen dengan kuat pencahayaan eksisting dan pengganti. Metode perhitungan lumen ini menjadi referensi dalam menentukan arus cahaya yang diperlukan oleh lampu pada ruang tersebut berdasarkan nilai minimum arus cahaya yang dihasilkan. Berdasarkan tabel 1 dapat dikatakan bahwa jumlah lampu dan arus cahaya lampu yang digunakan merupakan bagian penting agar mencapai pencahayaan yang ideal pada ruang. Selain itu, penempatan titik lampu pada ruang juga merupakan hal yang penting untuk diperhatikan agar persebaran cahaya pada ruang dapat merata. Hasil studi ini sesuai dengan teori pada penelitian yang menyatakan bahwa apabila luas ruang semakin besar, maka jumlah dari lampu yang digunakan akan semakin banyak. Oleh karena itu, hal ini dapat dilakukan dengan cara mengurangi jumlah lampu yang digunakan, namun menggunakan lampu dengan arus cahaya yang lebih tinggi. Dengan mengatur arus cahaya dan jumlah lampu yang digunakan pada suatu ruang, maka penggunaan listrik pada ruang tersebut dapat diminimalisir [19]. Contoh perhitungan kuat penerangan menggunakan metode lumen (persamaan 3) pada ruang K 205 kondisi eksisting adalah sebagai berikut:

$$
\begin{gathered}
E=\frac{\Phi \times \eta \times \mathrm{N}}{A} \\
E=\frac{1200 \text { lumen } \times 0,5 \times 10 \text { buah }}{55,1 \mathrm{~m}^{2}} \\
E=108,89 \text { lux }
\end{gathered}
$$

Dari contoh perhitungan di atas maka dapat dikatakan kondisi eksisting dari K 205 masih di bawah standar penerangan ruang ( $\geq 250$ lux). Oleh karena itu, dengan menggunakan metode perhitungan lumen (persamaan 3), maka akan diketahui arus cahaya minimum sebuah lampu yang digunakan seperti pada ruang K 205 dengan aasumsi menggunakan 12 buah lampu.

$$
\begin{aligned}
\Phi & =\frac{E \times A}{\eta \times N} \\
\Phi & =\frac{250 \text { lux } \times 55,1 \mathrm{~m}^{2}}{0,5 \times 12 \text { buah }} \\
\Phi & =2295,83 \text { lumen }
\end{aligned}
$$

Hasil perhitungan arus cahaya minimum lampu yang digunakan, maka dapat dikatakan apabila ruang K 205 mencapai kuat pencahayaan sebesar 250 lux, harus menggunakan lampu dengan arus cahaya minimum 
sebesar 2295,83 lumen. Pada penelitian ini penggantian lampu dan titik lampu yang dilakukan pada ruang tersebut yaitu menggunakan lampu dengan arus cahaya sebesar 2500 lumen dan dipasang sebanyak 12 buah lampu.

$$
\begin{aligned}
E & =\frac{\Phi \times \eta \times N}{A} \\
E & =\frac{2500 \text { lumen } \times 0,5 \times 12 \text { buah }}{55,1 \mathrm{~m}^{2}} \\
E & =272,23 \text { lux }
\end{aligned}
$$

Dari hasil perhitungan, membuktikan bahwa dengan mengganti lampu dan jumlah lampu yang digunakan dapat menciptakan kuat penerangan ruang yang sesuai dengan standar pencahayaan.

\subsection{Analisis Hasil Data Konsumsi Energi}

Tujuan dari skenario penggantian yang dilakukan adalah menggunakan lampu hemat energi sehingga konsumsi energi dapat lebih rendah. Analisis energi ini dilakukan pada dua buah skenario penggantian. Hasil rekapitulasi dari perbandingan konsumsi energi pada kondisi eksisting dan penggantian akan disajikan pada tabel 2 .

Tabel 2. Data Konsumsi Energi Lampu pada Kondisi Eksisting dan Kondisi Penggantian

\begin{tabular}{ccc}
\hline Ruang Kuliah & $\begin{array}{c}\text { Konsumsi Energi } \\
\text { Per Hari Kondisi } \\
\text { Eksisting [Wh] }\end{array}$ & $\begin{array}{c}\text { Konsumsi Energi } \\
\text { Per Hari Kondisi } \\
\text { Penggantian [Wh] }\end{array}$ \\
\hline K 101 & 5760 & 2480 \\
K 102 & 11520 & 4960 \\
K 103 & 11520 & 4960 \\
K 104 & 5760 & 2480 \\
K 105 & 5760 & 2480 \\
K 106 & 11520 & 4960 \\
K 107 & 3840 & 4340 \\
K 108 & 5760 & 2480 \\
K 201 & 1920 & 2480 \\
K 202 & 3840 & 4340 \\
K 203 & 1920 & 2480 \\
K 204 & 4480 & 4340 \\
K 205 & 1600 & 1860 \\
K 206 & 5120 & 4340 \\
K 207 & 3840 & 4340 \\
K 208 & 1920 & 2480 \\
K 209 & 8640 & 3720 \\
K 210 & 8640 & 3720 \\
K 211 & 8640 & 3720 \\
Total Konsumsi & 112000 & 66960 \\
Energi Per Hari [Wh] & & \\
\hline
\end{tabular}

Hasil konsumsi energi ini merupakan hasil perkalian antara daya yang digunakan seluruh lampu pada ruang kuliah dengan durasi waktu yang digunakan pada lampu. Asumsi waktu yang digunakan pada ruang kuliah per hari adalah 10 jam dari pukul 08.00 hingga 18.00. Berdasarkan tabel 3 dapat dikatakan bahwa jumlah energi yang dibutuhkan lampu kondisi eksisting lebih tinggi daripada konsumsi energi pada kondisi penggantian. Hal ini dikarenakan pada kondisi eksisting, lampu yang digunakan pada ruang kuliah masih menggunakan lampu fluoresen. Lampu fluoresen ini menggunakan daya yang cukup besar sehingga konsumsi energi pada ruang kuliah akan meningkat. Sedangkan pada saat dilakukan penggantian menggunakan lampu LED, konsumsi energi menjadi lebih rendah. Hal ini dikarenakan LED memiliki karakteristik yang hemat daya.

\section{Kesimpulan}

Pada studi ini dapat disimpulkan bahwa jenis, arus cahaya, jumlah, maupun posisi dari titik lampu sangat berpengaruh terhadap persebaran dan tingkat pencahayaan pada ruang kuliah. Selain itu, pada studi ini terbukti juga bahwa penggunaan cahaya matahari pada pagi dan siang hari untuk menghemat penggunaan lampu pada ruang. Hal ini sejalan dengan metode penganturan pencahayaan yang dilakukan pada penelitian Luigi [20] yang menyatakan bahwa perlunya manajemen yang cerdas terhadap efisiensi energi, kualitas pencahayaan dan pengeluaran biaya yang efisien. Untuk merealisasikan sistem pengaturan cerdas ini hal yang perlu diperhatikan antara lain efisiensi alat, desain pencahayaan yang baik, dan sistem kontrol terhadap pencahayaan. Lampu LED dapat dikatakan merupakan sumber penerangan yang paling efektif, andal, dan umur yang lama. Hasil ini sesuai dengan studi yang dilakukan oleh Daniel dan tim, yang telah melakukan penelitian pencahayaan pada ruang kuliah dengan mengganti lampu fluoresen menjadi lampu LED. Hasil penghematan energi dari kondisi eksisting dengan kondisi penggantian adalah lebih dari 50\% [21]. Selain itu, pada beberapa penelitian yang sudah dilakukan menyatakan bahwa penggunaan LED memiliki efisiensi yang sangat tinggi, faktor daya yang bagus, dan memiliki distorsi yang cukup rendah dengan teknologi LED saat ini [22]. Adapun kelemahan dari LED adalah bergantung pada suhu lingkungan di sekitar lampu tersebut. Sehingga perlu adanya pengaturan agar LED tidak cepat panas sehingga umur pakai lampu bisa lebih lama. Studi terkait mengatasi kelemahan dari lampu LED dan feasibilitas lampu LED yang dapat digunakan sebagai lampu darurat apabila listrik padam perlu diperdalam lagi untuk studi selanjutnya.

\section{Ucapan Terima Kasih}

Penelitian ini didanai oleh hibah penelitian HIBAH PUTI tahun 2020 dari Direktorat Riset dan Pengabdian Masyarakat Universitas Indonesia (DRPM-UI).

\section{Referensi}

[1]. M. S. Rea, The IESNA Lighting Handbook, New York: The Illuminating Engineering Society of North America, 2000.

[2]. T. Zhang, H. Cheng, L. Xia and X. Liu, "The Influence of Indoor LED Lighting in Depth Perception in Real World," in 15th China International Forum on Solid State Lighting: International Forum on Wide Bandgap Semiconductor China (SSLChina: IFWS), Shenzhen, 2018. 
[3]. D. Pavlov, I. Petrinska, D. Ivanov and K. Nikolova, "Energy efficient lighting solutions for educational buildings and clasrooms," in 11th Electrical Engineering Faculty Conference, Varna, 2019.

[4]. C. Darmasetiawan and L. Puspakesuma, Teknik Pencahayaan dan Tata Letak Lampu, Jakarta: PT. Grasindo, 1991.

[5]. J. H. Saputro, T. Sukmadi and Karnoto, "Analisa Penggunaan Lampu LED Pada Penerangan Dalam Rumah," Transmisi, vol. 1, no. 15, pp. 19-27, 2013.

[6]. H. Nayomi, Peluang Pemanfaatan Lampu LED Sebagai Sumber Penerangan, Depok: Universitas Indonesia, 2013

[7]. N. Narendran and Y. Gu, "Life of LED-Based White Light Sources," Journal Of Display Technology, vol. 1, no. 1, pp. 167-171, 2005.

[8]. G. Lu, C. Yuan, H. Tang, C. Wong, X. Fan and G. Zhang, "Cause Analysis on Highly Depreciated Indoor LED Product in CSA020," in 10th China International Forum on Solid State Lighting (ChinaSSL), Beijing, 2013.

[9]. Y. Zhang, Y. Wang, D. Li, L. Liu, X. Li and N. Zou, "Indoor Illumination Based On Distributive LED Lights," in International Conference on Communication Technology and Application, Beijing, 2011.

[10]. L. S. Pereira, Y. Pontes and F. M. da Costa, "Energy Efficiency In The Replacement Of Fluorescent Lamps By LED: Application In A Store," in Brazilian Power Electronics Conference, Juiz de Fora, 2017.

[11]. A. Suresh, J. P. Salis and S. K.R, "Lighting Optimization to Save Energy in an Indoor Sport Facility," in Second International Conference on Advanced Computational and Communication Paradigms (ICACCP), Gangtok, 2019.

[12]. A. Suresh, J. P. Salis and S. K.R, "Lighting Optimization to Save Energy in an Indoor Sport Facility," in Second International Conference on Advanced Computational and Communication Paradigms (ICACCP), Gangtok, 2019.

[13]. Muhaimin, Teknologi Pencahayaan, Malang: PT. Refika Aditama, 2001.
[14]. A. Rahardjo, Instalasi Penerangan Bangunan, Depok: Departemen Teknik Elektro, 2019.

[15]. M.-T. Chen, S.-H. Lin and D.-J. Lin, "Implemantation of High Power LED Driving Source with High Efficiency and High Power Factor for Indoor Illumination," in International Symposium on Computer, Consumer and Control (IS3C), Taichung, 2018.

[16]. A. W. Levy, "Lighting Controls, Patterns of Lighting Consumption, and Energy Conservation," IEEE Transaction On Industry Application, Vols. IA-16, no. 3, pp. 419-427, 1980.

[17]. M. L. Aninditio, A. Rahardjo and C. Hudaya, "Lighting Replacement Analysis at Classrooms of Engineering Center, Faculty of Engineering, Universitas Indonesia," in International Conference on Quality in Research (QiR), Nusa Dua, 2017.

[18]. S. Bunjongjit, M. Ngaopitakkul and M. Leelajindakrairerk, "Analysis of Harmonics in Indoor Lighting System with LED and Fluorescent Luminaire," in 3rd International Future Energy Electronics Conference and ECCE Asia, Kaohsiung, 2017.

[19]. W. N. Muhamad, M. Y. M. Zain, N. Wahab, N. H. A. Aziz and R. A. Kadir, "Energy Efficient Lighting System Design for Building," in International Conference on Intelligent Systems, Modelling, and Simulation, Liverpool, 2010.

[20]. L. Martirano, "Lighting Systems to Save Energy in Educational Classrooms," in 10th International Conference on Environment and Electrical Engineering, Rome, 2011.

[21]. D. F. Espejel-Blanco, J. A. Hoyo-Montano, J. A. Orrante-Sakanassi and J. A. Federico-Rivera, "Comparison of Energy Consumption of Fluorescent VS LED Lighting System of an Academic Building," in IEEE Conference on Technologies for Sustainability (SusTech), California, 2018.

[22]. C.-A. Cheng, C.-H. Chang, H.-L. Cheng, E.-C. Chang and C.-C. Lai, "A Novel LED Tube Lamp Driver with Power-Factor Correction for Indoor Lighting Application," in IEEE 7th Global Conference on Consumer Electronics (GCCE), Nara, 2018. 